\title{
Rising rates of second stage caesarean section and its impact on maternal outcome
}

\author{
Shanmugapriya Kumaresan*, Malarvizhi Loganathan
}

Department of Obstetrics and Gynecology, Government Dharmapuri Medical College, Dharmapuri, Tamil Nadu, India

Received: 14 June 2018

Accepted: 18 June 2018

\section{*Correspondence:}

Dr. Shanmugapriya Kumaresan,

E-mail: drpriyakumaresan@gmail.com

Copyright: (C) the author(s), publisher and licensee Medip Academy. This is an open-access article distributed under the terms of the Creative Commons Attribution Non-Commercial License, which permits unrestricted non-commercial use, distribution, and reproduction in any medium, provided the original work is properly cited.

\begin{abstract}
Background: There is an alarming rise in caesarean section leading to increased adverse outcomes for both the mother and fetus when compared with vaginal delivery. With this increasing caesarean section rate, there is a concerning increase in the rate of second stage caesarean section. This study highlights includes the rate of caesarean deliveries in the second stage of labour, the indications for delivery and the associated maternal morbidity in this cohort of women.

Methods: This was a prospective cohort review of all women with a singleton, cephalic fetus at term delivered by caesarean section in the second stage of labor between July, 2016 and December 31, 2017 at government medical college hospital Dharmapuri. The main outcome measures were second stage caesarean section, indications and its maternal morbidity.

Results: 250 women underwent caesarean delivery in the advanced labor. Among the 250 patient's majority of them were in the age group of 21-30 yrs. about $76 \%$ of the patients were primigravidae and only the remaining $24 \%$ were multigravida. The commonest indications for doing caesarean section in the second stage of labor was cephalo pelvic disproportion and non-reassuring fetal heart rate patterns. The difficult task was delivery of the deeply engaged head, the increased likelihood of intraoperative and post-operative complications.

Conclusions: Cesarean sections done in second stage of labor are associated with several intra-operative maternal complications and morbidity.
\end{abstract}

Keywords: Caesarean complications, Emergency caesarean section, Maternal morbidity, Neonatal morbidity, Second stage of labor

\section{INTRODUCTION}

Caesarean section represents the most significant interventional operative procedure in all of obstetrics. Its development and meaningful application has helped us to provide safe motherhood and improved quality of life of mother and new born by avoiding serious delivery complications. The incidence of cesarean section has increased tremendously over the recent years. The rate of cesarean deliveries continues to increase despite efforts to constrain operative abdominal deliveries. This is a cause for concern because cesarean section is associated with higher likelihood of adverse outcomes for both mother and fetus as compared to vaginal delivery.

Second stage of labour begins when cervical dilatation is complete and ends with fetal delivery. Second stage interventions are the methods to facilitate delivery of the fetus in the form of assisted vaginal delivery or instrumental delivery. Risk factors for the prolonged $2^{\text {nd }}$ stage include epidural analgesia, occipito posterior position, longer $1^{\text {st }}$ stage of labour, nulliparity, short 
maternal stature, birth weight, and high station of head at complete cervical dilatation. ${ }^{1}$ Worldwide $30-40 \%$ of deliveries require some form of intervention which is usually cesarean section. Second stage cesarean is a challenging procedure with high materno fetal morbidity rates. There are multiple etiological factors for this increasing trend of second stage caesareans; there are pitfalls in the supervision of second stage decision making, increasing litigious issues related to maternal morbidity. Primary cesarean section has many important implications for future pregnancies and subsequent labour and delivery.

The morbidity related to a prolonged second stage is directly correlated with the incidence of extension of uterine angles and prolonged surgical time, bladder injury, and increased incidence of postpartum haemorrhage and hospital stay. ${ }^{2}$ The objectives of the present study were to study the indications for second stage caesarean section, methods of delivery of the deeply engaged head, the intra operative and postoperative complications, and perinatal outcome.

\section{METHODS}

This prospective cross-sectional study was conducted

in the department of OBG at Government Dharmapuri medical college hospital, Dharmapuri from July 2016 to December 2017. Sample size was 250.

The data was collected from the labor room, both booked as well as unbooked patients were included.

\section{Inclusion criteria}

- $\quad$ Primi /multi gravida with term gestation

- Singleton pregnancy with vertex presentation.

\section{Exclusion criteria}

- Previous caesarean section

- Maternal co morbid condition.

The following parameters were monitored in the study group.

Table 1: Second stage parameters.

\begin{tabular}{|lll|}
\hline Indicators & Nullipara & Multipara \\
\hline Average second stage & $50 \mathrm{~min}$ & $20 \mathrm{~min}$ \\
\hline Protracted dilatation & $<1.2 \mathrm{~cm} /$ hour & $<1.5 \mathrm{~cm} /$ hour \\
\hline Protracted descent & $<1 \mathrm{~cm} /$ hour & $<2 \mathrm{~cm} /$ hour \\
\hline Arrest of dilation & $>2$ hours & $>2$ hours \\
\hline Arrest of descent & $>2$ hours & $>1$ hours \\
\hline
\end{tabular}

Partograph was used in the study to monitor the progress of labour, except for those patients who were referred in the late second stage of labour (Table 2) the average waiting time in the second stage was $50 \mathrm{~min}$ for nulliparous and $20 \mathrm{~min}$ for multiparous women. The rate of dilatation, descent of the presenting part was monitored using partograph. Protraction is defined as a slow rate of cervical dilatation or descent, which for nulliparas was less than $1.2 \mathrm{~cm}$ dilatation per hour or less than $1 \mathrm{~cm}$ descent per hour. For multiparas, protraction was defined as less than $1.5 \mathrm{~cm}$ dilatation per hour or less than $2 \mathrm{~cm}$ descent per hour (Table 1).

Table 2 gives the trend of deliveries in our hospital. Since our hospital is a tertiary care referral centre, the caesarean section rate comes around $40-41 \%$, and the no of referrals have increased drastically.

Table 2: Trend of deliveries in our hospital over three years.

\begin{tabular}{|llll|}
\hline & 2015 & 2016 & 2017 \\
\hline Total deliveries & 7246 & 8515 & 7957 \\
\hline Vaginal deliveries & 3489 & 4418 & 4007 \\
\hline Assisted deliveries & 102 & 207 & 185 \\
\hline Elective LSCS & 338 & 451 & 460 \\
\hline Emergency LSCS & 3317 & 3439 & 3305 \\
\hline
\end{tabular}

\section{RESULTS}

This prospective cross-sectional study was conducted in the department of OBG at Government Dharmapuri medical college hospital, Dharmapuri from July 2016 to December 2017.the following were the study results (Table 3-8) which were analysed and reported.

Table 3: Maternal demographic features.

\begin{tabular}{|ll|}
\hline Age & Percentage \\
\hline $18-21$ Years & $86(34.4 \%)$ \\
\hline $22-30$ Years & $104(41.6 \%)$ \\
\hline $31-37$ Years & $60(24 \%)$ \\
\hline
\end{tabular}

Table 4: Maternal characteristics.

\begin{tabular}{|lll|}
\hline 0 BS code & No & Percentage \\
\hline Primi Gravida & 190 & $76 \%$ \\
\hline Multi Gravida & 60 & $24 \%$ \\
\hline
\end{tabular}

Among the 250 patient's majority of them were in the age group of $21-30$ years $(41.6 \%)$ (Table 2$)$. about $76 \%$ of the patients were primigravidae and only the remaining $24 \%$ were multigravida (Table 3). Majority were booked patients, only $1 \%$ was unbooked from remote areas near the district. The commonest indications for doing caesarean section in the second stage of labour was cephalo pelvic disproportion, fetal distress and obstructed labour.

A few of them $(2.8 \%)$ (Table 5) went in for caesarean section following failed instrumentation. $90 \%$ of the cases of obstructed labour were delayed referral from primary health centres, and district hospitals nearby. The obstetrician needs to anticipate the possibility of difficult 
delivery of the fetal head during caesarean section. Different techniques are described in litera-ture to deliver the deeply impacted fetal head.

Table 5: Indications for caesarean section.

\begin{tabular}{|ll|}
\hline Indications & Percentage \\
\hline Cephalopelvic disproportion & $87(34.8 \%)$ \\
\hline Deep transverse arrest & $24(9.6 \%)$ \\
\hline MSAF/non-reassuring FHR tacing & $46(18.4 \%)$ \\
\hline Arrest of descent & $42(16.8 \%)$ \\
\hline Persistent right occipito-posterior & $17(6.8 \%)$ \\
\hline Failed instrumentation & $7(2.8 \%)$ \\
\hline Obstructed labour & $46(18.4 \%)$ \\
\hline
\end{tabular}

The first is the "head push" or abdominovaginal delivery technique. After the transverse incision is made in the uterus, the assistant's hand in the vagina cups the baby's head in the palm and fingers and lifts the head up into the incision. The surgeon's hand is then inserted into the incision beneath the fetal head and completes the delivery. $^{3}$

Table 6: Methods of delivery of the baby in second stage c-section.

\begin{tabular}{|ll|}
\hline \multicolumn{1}{|c}{ Method } & Proportion \\
\hline Conventional method & $43(17.2 \%)$ \\
\hline Push method & $68(27.2 \%)$ \\
\hline Patwardhan technique & $112(44.8 \%)$ \\
\hline Reverse breech extraction (pull method) & $27(10.8 \%)$ \\
\hline
\end{tabular}

\section{Patwardhan technique}

Patwardhan technique Was introduced in 1957 by Dr. Patwardhan. In cases of occipito-anterior and transverse positions, with the head deeply impacted in the pelvis, incision is made in the lower uterine segment, shoulders are present usually at incision level.

- The anterior shoulder is delivered out by hooking the arm first.

- With gentle traction on this shoulder, the posterior shoulder is also delivered out.

- Next the surgeon holds the trunk of the baby gently with both thumbs parallel to spine and with fundal pressure given by the assistant, the buttocks are delivered followed by leg.

\section{Modified Patwardhan Technique $e^{4,5}$}

In case of occipito-posteior position with the head deeply into the pelvis, the anterior shoulder is delivered of first followed by delivering the same side leg.

- In other side leg is then delivered gently followed by same side arm.

- By gently pulling baby legs buttocks and the trunk of baby and are delivered.
- $\quad$ Lastly the baby head is delivered.

In the reverse breech extraction method, after opening the uterus, the surgeon introduces a hand through the uterine incision towards the upper segment, grasps both feet, and gently pulls the fetus up to extract it6. In present study many of them followed patwardhan technique $(44.8 \%)$, only a few (10.8\%) were delivered by reverse breech extraction technique (Table 6).

Table 7: Intraoperative complications of second stage c-section.

\begin{tabular}{|l|l|}
\hline Complications & Proportion \\
\hline Uterine atony & $83(33.2 \%)$ \\
\hline Uterine wound extension & $65(26 \%)$ \\
\hline Angle haematoma & $31(12.4 \%)$ \\
\hline Uterine artery ligation & $12(4.8 \%)$ \\
\hline Blood tansfusion & $23(9.2 \%)$ \\
\hline Broad ligament haematoma & $2(0.8 \%)$ \\
\hline Bladder laceration & $2(0.8 \%)$ \\
\hline Posterior wall repair /laceration & $2(0.8 \%)$ \\
\hline Rupture uterus & - \\
\hline
\end{tabular}

The remaining adopted the conventional method and the push technique. Over all the incidence of complications were minimal with Patwardhan technique. ${ }^{5}$ Intraoperative complications of emergency cesarean section done in advanced labour add significantly to maternal mortality and morbidity in terms of increased risk of cervical tears, extension of uterine incision and excessive intra-operative haemorrhage. ${ }^{7,8}$ The commonest intra operative complication encountered was atonicity of the uterus (Table 7), which might be due to various factors like prolonged labour, inducing agents and drugs used for cervical ripening. Uterine atonicity was noted in $33.2 \%$ of patients. $26 \%$ of patients had uterine wound extension (Table 7) due to associated difficulty in delivering the deeply engaged head.

Table 8: Postoperative complications of second stage caesarean section.

\begin{tabular}{|ll|}
\hline Complications & Proportion \\
\hline Prolonged catheterization & $95(38 \%)$ \\
\hline Blood stained urine & $87(34.8 \%)$ \\
\hline Post op fever & $26(10.4 \%)$ \\
\hline Respiratory complications & $14(5.6 \%)$ \\
\hline Paralytic ileus & $17(6.8 \%)$ \\
\hline Wound infection & $18(7.2 \%)$ \\
\hline Wound resuturing & $3(1.2 \%)$ \\
\hline Rectus sheath haematoma & $4(1.6 \%)$ \\
\hline Sepsis & $2(0.8 \%)$ \\
\hline Venous thromboembolism & - \\
\hline Relaparotomy & $1(0.4 \%)$ \\
\hline
\end{tabular}

Bladder injury is the commonest urinary tract injury associated with caesarean section which occurs in about $0.3 \%$ of deliveries in present study $0.8 \%$ of patients 
developed minor lacerations in the bladder which was treated conservatively. ${ }^{9} \quad$ After the immediate threat of haemorrhage is over, the most common complications are due to infection of the genito-urinary tract and the surgical wound the most common infections following caesarean are endometritis, septic pelvic thrombophlebitis ,upper respiratory tract infection, urinary tract infection and occasionally pelvic abscess.

In present study the major post-operative complication was due to urinary tract involvement, majority (87) (Table 8) developed blood stained urine, due to drawn up bladder, bladder wall being edematous and congested, very close proximity to lower uterine segment and bladder. The respiratory complications like atelectasis, pneumonia was common among obese and patients with pre-existing upper respiratory tract infection.

Wound infection was noted in 18 patients, of which only 3 patients underwent resuturing, the remaining were treated conservatively. Exploratory relaparotomy was done for one patient (Table 8), the reason was rectus sheath haematoma which was identified 6 hours later. wound exploration was done immediately, blood and blood products given, the patient recovered well.

Since early ambulation, and adequate hydration was insisted for all patients, we did not come across any case of venous thromboembolism during the study period.

\section{DISCUSSION}

The present study shows that the caesarean section performed in the second stage of labour have significantly higher maternal and neonatal morbidity. This high rate of caesarean section in current study is because of the fact that our hospital is a tertiary referral hospital where all emergency cases are dealt.

In the study by Malathi et al, most of women were between 21-30 years of age (58\%) and primigravida $(72 \%) .{ }^{10}$ Higher rate of second stage caesarean section in young primigravida woman was probably due to higher incidence of rigid perineum, feto-pelvic disproportion and uterine inertia.

The most common indications for caesarean section in the present study group was cephalopelvic disproportion $(34.8 \%)$ and non-reassuring fetal heart rate patterns $(18.4 \%)$. Uterine atonicity $(33.2 \%)$ was the commonest intra operative complication encountered, most of which were treated by medical management, few cases $(4.8 \%)$ required uterine artery ligation. The difficult task was delivering the deeply impacted head, majority were delivered by Patwardhan technique $(44.8 \%)$, since the Patwardhan technique reported lesser operative time and the incidence of complications were minimal. ${ }^{11}$

Emergency cesarean section done in advanced labor should be taken as a high-risk procedure. Use of prophylactic antibiotics, arrangement of fresh blood and involvement of senior obstetrician to operate on laboring mother and use of modified techniques to deliver deeply impacted fetal head is important to reduce complications. $^{12}$

\section{CONCLUSION}

Cesarean section in full cervical dilation is an undesirable situation associated with intra operative and postoperative complications. careful judgement for cephalopelvic disproportion, attendance of skilled health care provider during labour and deliveries and implementation of effective instrumental delivery can bring down the incidence to some extent. The focus should be on ensuring normal progression of labour, proper use of the partogram, pain relief measures, oxytocin augmentation and the promotion of effective pushing techniques.

Funding: No funding sources

Conflict of interest: None declared

Ethical approval: The study was approved by the Institutional Ethics Committee

\section{REFERENCES}

1. Allen VM, O'Connell CM, Baskett TF. Maternal and perinatal morbidity of caesarean delivery at full cervical dilatation compared with caesarean delivery in the first stage of labour. BJOJ. 2005;112:986-90.

2. Cebekulu L, Buchman EJ. Complications associated with caesarean section in the second stage of labour. Int J Gynecol Obstet. 2006;95:110-4.

3. Landesman $\mathrm{R}$, Graber EA. Abdominovaginal delivery: modification of the cesarean section operation to facilitate delivery of the impacted head. Am J Obstet Gynecol. 1984;148:707-10.

4. Fasubaa OB, Ezechi OC, Orji EO, Ogunniyi SO, Akindele ST, Loto OM, et al. Delivery of the impacted head of the fetus at caesarean section after prolonged obstructed labour: a randomised comparative study of two methods. J Obstet Gynaecol. 2002;22:375-8.

5. Levy R, Chernomoretz T, Appelman Z, Lein D, OR $\mathrm{Y}$, Hagay ZJ. Head pushing versus reverse breech extraction in cases of impacted fetal head during cesarean section. Eur J Obstet Gynecol Reprod Biol. 2005;121:24-6.

6. Fasubaa OB, Ezechi OC, Orji EO, Ogunniyi SO, Akindele ST, Loto OM, Okogbo FO. Delivery of the impacted head of the fetus at caesarean section after prolonged obstructed labor, a randomized comparative study of two methods. J Obstet Gynecol. 2002;22:375-8.

7. Sung JF, Daniels KI, Brodzinsky L, El-Sayed YY, Caughey AB, Lyell DJ. Caesarean delivery outcome after a prolonged second stage of labor. Am J of Obstet Gynecol. 2007;197(306):e1-5. 
8. A retrospective comparative study of feto-maternal outcome in first and second stage caesarean section. Int J Reprod Contracept Obstet Gynecol. 2016;5:2282-6.

9. Philipps MG, Watabe B, Clemons JL, Weitzen S, Myers DL. Risk factors for bladder injury during caesarean delivery. Obstet Gynecol. 2005 ;105(1):156-60.

10. Malathi J, Sunita V. Comparison of obstetric outcome between first and second stage caesarean section in rural tertiary hospital. Int $\mathbf{J}$ Pharma Biomed Res. 2012;3:222-5.

11. Saha PK, Gulati R, Goel P, Tandon R, Huria A, Second Stage Caesarean Section: Evaluation of
Patwardhan Technique. J Clinic Diag Res. 2014;8(1):93-5.

12. Alexander JM, Leveno KJ, Rouse DJ, Landon MB, Sponge CY, Varner MW, et al. Comparison of maternal and infant outcomes from primary caesarean delivery during the second compared with first stage of labor. Obstet Gynecol. 2007;109:91721.

Cite this article as: Kumaresan S, Loganathan M, Rising rates of second stage caesarean section and its impact on maternal outcome. Int J Reprod Contracept Obstet Gynecol 2018;7:2681-5. 